\title{
Risks to health of the population of the nonindustrial city from quality of atmospheric air
}

\author{
I. Abdikadirova ${ }^{1}$, B. Zasorin ${ }^{1}$, L. Yermukhanova ${ }^{1}$, V. Sabyrakhmetova ${ }^{1}$, A. Zhexenova ${ }^{1}$, \\ and U. Urazova ${ }^{2}$ \\ ${ }^{1}$ Marat Ospanov West Kazakhstan State Medical University, The Republic of Kazakhstan \\ ${ }^{2}$ Astana Medical University, The Republic of Kazakhstan
}

\begin{abstract}
Risk assessment to public health living in the environmental problems is of great importance for humans today. However, the main attention is paid to major industrial centers, while for cities not having developed industries such studies are rare. The study of the intensity and structure of chemical air pollution was conducted to determine the risk levels for human health from effects of the chemical air pollution in residential areas of Aktau city (West Kazakhstan). Method of retrospective analysis of emissions into the atmosphere was used, and damage to health was determined in accordance with the risk assessment procedure. We take into account the major pollutants, the city being in the air basin - sulfur dioxide, hydrogen sulfide, carbon monoxide, nitrogen oxides, ammonia and total hydrocarbons. The main threat to children's health is caused by common hydrocarbons $(88 \%)$, nitrogen oxides $(5 \%)$, and ammonia $(3 \%)$. The estimated cancer risk is defined at the level of $10^{-3}$ to $10^{-4}$, it corresponds to the limits and requires regular monitoring.

Key words: risk evaluation, population morbidity, air pollution.
\end{abstract}

\section{Introduction}

Health risk assessment system allows us to obtain not only qualitative, but also quantitative characterization of the influence of the environment on population's health before the onset of the effects of this influence. It distinguishes risk assessment of epidemiological methods of analysis and makes it possible to predict the result and work on the basis of management decisions to minimize adverse effects, based on existing chemical environmental factors, monitoring of the environment and the population's health. In this regard, the health risk assessment system can be easily integrated into the overall management system and decision-making in administrative practice. The ability to assess health of the population or the extent of its loss by financial categories is important in today's economic environment, both for health and the management system. Health risk assessment system allows us to determine the health risk from a variety of factors $[1,2]$.

At present, atmospheric air is the leading object of the environment, which is connected with the greatest part of all health risks [3]. This problem is significantly worsened at the border of the XX-XXI centuries due to the increase of capacity of thermal power plant, 
petrochemical metallurgy, and as a result of the growth of units of vehicles in urban areas $[4,5]$.

Considerable development of the Caspian region of Kazakhstan which is characterized by hot and humid climate that leads to regional specificity in the evaluation of risks for health of the population living here is being continued.

Aktau is a port on the Caspian Sea, through which the main maritime transit of Kazakhstan goods is realized. There are not industrial plants polluting the air in the city but the network of transport companies is well developed.

The aim of this work is assessment of levels of the carcinogenic and non-carcinogenic risks from chemical factors of air pollution for population's health in Aktau.

\section{Materials and methods}

Risk assessment of public health is carried out by the usual method [6]. The risks were calculated for the following age groups: children ( $0-6$ years) [7], adolescents (14-16 years) and adults (over 20 years).

Monitoring data of the air quality of the city for a five-year period (2011-2015) was used as the information source. The reference concentration for chronic inhalation exposure was used for risk calculation. Comprehensive assessment of the carcinogenic risk was performed using the computer program "RISK * ASSISTANT", in accordance with the methodology set out in the documents: Risk Assessment Guidance for Supperfund. Vol. I: Human Health Evaluation Manual No. 540/189/002. (US EPA, 1989); Guidance for Risk Characterization (US EPA, 1995). Quantitative parameters for the evaluation of the carcinogenic risks were taken from the documents U.S. Environmental Protection Agency, Integrated Risk Information System, Environmental Criteria and Assessment Office, Office of Health and Environmental Assessment, Office of Research and Development (Cincinnati, 1993) [8].

Information on actual pollution of the atmospheric air of Aktau city (for a 5-year period) was received at the Department on consumers' rights protection of Mangystau region.

Calculation of non-carcinogenic risks taking into account vital organs and systems is made for the following pollutants of the atmospheric air as: sulphur dioxide, hydrogen sulphide, carbon monoxide, nitric oxides, ammonia, volatile organic compounds (VOC), and general hydrocarbons.

\section{Results and discussion}

During the first stage of the research the calculation of average annual and average daily concentration of contaminants was made. On the basis of given calculations, concentration of the substance, entering the body with the atmospheric air, taking into consideration $\mathrm{mg} / \mathrm{kg}$ of the body weight (for the mentioned period of time) was determined.

Hazard quotient of carcinogenic effects and hazard index for all the mentioned above substances was calculated. Besides, hazard index for every vital organ and system was calculated. Calculation of the complex air pollution index $\left(\mathrm{API}_{5}\right)$ for five substances with the largest values is made by the formula: $\mathrm{API}_{5}=\Sigma(\mathrm{g}$ cp.i/MAC (maximum allowable concentration)) (i) $\mathrm{Ci}$ where $\mathrm{g}$ cp.i is the average concentration of the pollutant;

$\mathrm{MAC}_{\mathrm{i}}$ is the average daily MAC of the pollutant;

$\mathrm{Ci}$ is a coefficient that depends on the hazard class of the pollutant, taken to be 1.7, 1.3, 0.1 and 0.9 , respectively, for the 1,2, 3 and 4 hazard classes of the contaminant. 
The multiplicity of MAC excess $(K)$, including values less than 1 , is established by dividing the existing concentration of the substance in the air by the amount of daily average MAC according to the formula:

$$
K=\frac{C}{M A C}
$$

where:

$C$ - the existing concentration of this substance in the air in different periods averagely over time (average daily or average annual);

Characteristics of the risk of development of non-carcinogenic effects for individual substances are based on the calculation of the hazard factor using the formula:

$$
\mathrm{HQ}=\mathrm{AD} / \mathrm{RfD} \text { or } \mathrm{HQ}=\mathrm{AC} / \mathrm{RfC} \text {, where }
$$

HQ - hazard ratio;

$\mathrm{AD}$ - average dose, $\mathrm{mg} / \mathrm{kg}$;

$\mathrm{AC}$ - average concentration, $\mathrm{mg} / \mathrm{m}^{3}$;

$\mathrm{RfD}$ - reference (safe) dose, $\mathrm{mg} / \mathrm{kg}$;

$\mathrm{RfC}$ - reference concentration (safe), $\mathrm{mg} / \mathrm{m}^{3}$.

The hazard ratio is calculated separately for the conditions of short-term (acute), subacute and long-term exposure to chemicals. In this case, the averaging period of the exposures and the corresponding safe exposure levels should be similar.

Characteristics of the risk of developing non-carcinogenic effects in the combined and complex effects of chemical compounds are based on the calculation of the hazard index (HI). The hazard index for the conditions of simultaneous intake of several substances in the same way (for example, inhalation or oral) is calculated by the formula:

$$
\mathrm{HI}=\underset{\mathrm{I}}{\operatorname{Sum}} \text { of } \mathrm{HQ} \text {, where }
$$

HQ - hazard ratios for individual components of the mixture $i$ of the active substances. Received results are presented in Table 1.

Table 1. Hazard quotient (HQ) of non-carcinogenic effects for population of Aktau.

\begin{tabular}{|l|c|c|c|l|}
\hline Substance & Children & Adolescents & Adults & Vital organs \\
\hline $\begin{array}{l}\text { Sulphur } \\
\text { dioxide }\end{array}$ & 0.039 & 0.039 & 0.036 & Respiratory organs \\
\hline $\begin{array}{l}\text { Hydrogen } \\
\text { sulphide }\end{array}$ & 1.0 & 0.36 & 0.23 & Respiratory organs \\
\hline $\begin{array}{l}\text { Carbon } \\
\text { monoxide }\end{array}$ & 0.389 & 0.139 & 0.091 & $\begin{array}{l}\text { Blood, cardio-vascular system, } \\
\text { physical development, central } \\
\text { nervous system }\end{array}$ \\
\hline $\begin{array}{l}\text { Nitric } \\
\text { oxides }\end{array}$ & 2.059 & 0.736 & 0.478 & $\begin{array}{l}\text { Respiratory organs } \\
\text { blood (MetHb formation) }\end{array}$ \\
\hline $\begin{array}{l}\text { Ammonia } \\
\text { fmong }\end{array}$ & 1.313 & 0.471 & 0.872 & Respiratory organs \\
\hline $\begin{array}{l}\text { General } \\
\text { hydrocarb } \\
\text { ons }\end{array}$ & 37.023 & 13.227 & 8.581 & $\begin{array}{l}\text { Eyes, respiratory organs, liver, } \\
\text { kidneys, central nervous system }\end{array}$ \\
\hline
\end{tabular}

Conducted calculations of non-carcinogenic risks indicate that children population of Aktau city are exposed to maximal risks for their health. In particular maximal ratings of HQ are established for general hydrocarbons and comprise 37.023. Hazard quotient 
indicators more than 1.0 are revealed for nitric oxides (2.059) and ammonia (1.313). Hazard quotient of hydrogen sulphide is equal to one.

Risk level for the health of adolescents living in Aktau city due to the pollution of the atmospheric air is slightly lower. The same tendency as in the group of children from 0 to 6 years is detected in this group. However risk level for the health of adolescents is 2.3-3 times lower. So, Hazard quotient for general hydrocarbons is 13.227 and it is the only chemical substance with Hazard quotient $>1$.

Similar results have been received while evaluating Hazard quotient for the adult population.

Results on hazard index evaluation for every vital organ and system are presented in Table 2 .

General hazard index for children (from 0 to 6 years) is 41.895 . Hazard index for respiratory organs takes the first place and is equal to 41.506. Diseases of central nervous system take the second place (hazard index $=37.412$ ), liver and kidney impairments (hazard index $=37.023$ ) take the third place. Excess of hazard index for the diseases of blood and cardio-vascular system should be mentioned as well (2.448).

For adolescents, hazard index comprised 14.971. Among vital organs the respiratory organs (hazard index $=14.832$ ) are in the first place, the second place is for the diseases of central nervous system (hazard index $=13.366$ ), the third place - the kidney and liver diseases (hazard index $=13.227$ ).

In the group of adult population hazard index is 4 times lower comparing with children (0-6) and 1.45 times lower comparing with adolescents. Among the most vulnerable organs are respiration organs, central nervous system, kidneys and liver.

Table 2. Hazard index (HI) for different age groups of Aktau population.

\begin{tabular}{|l|c|c|c|}
\hline \multicolumn{1}{|c|}{ HI } & Children & Adolescence & Adults \\
\hline Common & 41.895 & 14.971 & 10.288 \\
\hline Physical development & 0.389 & 0.139 & 0.091 \\
\hline Kidney diseases & 37.023 & 13.227 & 8.581 \\
\hline $\begin{array}{l}\text { Diseases of the blood, } \\
\text { cardiovascular system }\end{array}$ & 2.448 & 0.875 & 0.569 \\
\hline $\begin{array}{l}\text { Diseases of the } \\
\text { respiratory system }\end{array}$ & 41.506 & 14.832 & 10.197 \\
\hline Disease of the CNS & 37.412 & 13.366 & 8.672 \\
\hline Liver diseases & 37.023 & 13.227 & 8.581 \\
\hline
\end{tabular}

Summarizing the obtained results, it can be argued that the maximum non-carcinogenic risk for exposure to chemical substances in the air pool of the residential territories is set for the children population (0-6 years) Aktau. High risk of developing diseases of the respiratory organs, central nervous system, liver and kidney and blood and cardiovascular system is noted. It should be emphasized that to the risk of developing these diseases total hydrocarbons, nitrogen oxides, ammonia and hydrogen sulphide, contained in the atmospheric air, also made their contribution.

In the second stage of calculation of risks to public health was the assessed risk of carcinogenic effects from exposure to chemical substances emitted into the atmosphere of city of Aktau. The calculation of individual carcinogenic risk was carried out using data on the amount of exposure and the values of the factors of the carcinogenic potential (slope factor, unit risk). As a rule, for carcinogenic chemicals, the additional probability of 
developing cancer of the individual throughout life (CR) is assessed taking into account the average daily dose over lifetime (LADD) - Table 3.

Table 3. LADD (life average daily dose) for non-carcinogenic effects $\mathrm{mg} /(\mathrm{kg} *$ day).

\begin{tabular}{|l|c|c|c|}
\hline & Children & Adolescence & Adults \\
\hline Sulfur dioxide & 0.471 & 0.413 & 0.264 \\
\hline Hydrogen sulfide & 0.013 & 0.011 & 0.007 \\
\hline Carbon monoxide & 7.51 & 6.56 & 4.21 \\
\hline Nitrogen oxides & 6.23 & 5.46 & 3.49 \\
\hline Ammonia & 0.844 & 0.738 & 0.473 \\
\hline Total hydrocarbons & 16.91 & 14.79 & 9.46 \\
\hline $\begin{array}{l}\text { Volatile organic } \\
\text { compounds }\end{array}$ & 2.11 & 1.83 & 1.17 \\
\hline \multicolumn{1}{|c|}{$\Sigma$} & 34.088 & 29.802 & 19.074 \\
\hline
\end{tabular}

The obtained data on the lifetime average daily dose of admission of harmful substances from the air (subject to continuing levels of air pollution) indicate that a group of children (0-6 years) have the maximum average daily concentration for the entire period of life. This is followed by adolescence and adults.

The results obtained were used to calculate individual and population carcinogenic risk for the population of Aktau.

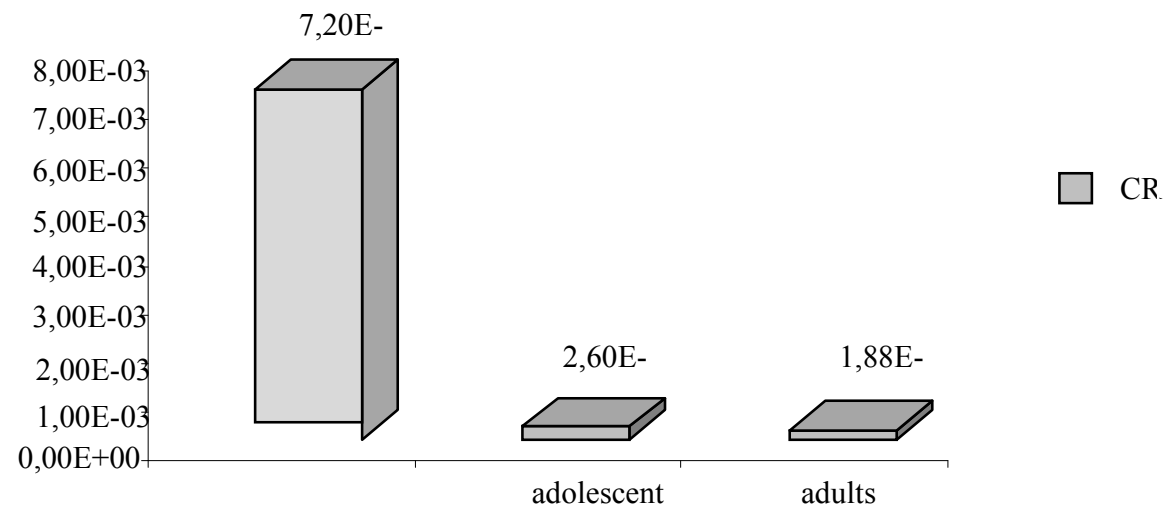

Fig. 1. Individual carcinogenic risk for the population of Aktau taking into account age.

The levels of carcinogenic risk for population's health of Aktau city in Fig. 1 show that the maximum individual risk of cancer is noted in the group of children population (0-6 years). The risk of malignancy among adolescent and adult population of the city on average is 30 times lower. Minimum individual cancer risk is determined among adults.

In a comparative risk characterization we used the value of the annual population risk (PCRa) - the estimated number of additional cancer cases during the year by sex and age (Fig. 2). 


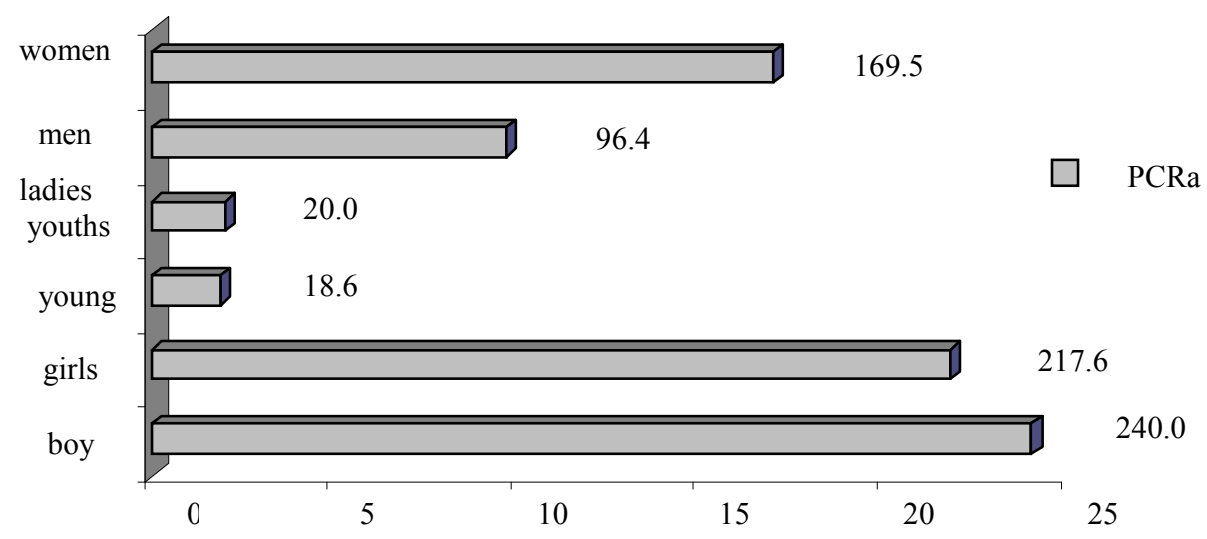

Fig. 2. Carcinogenic risks for the population of Aktau by sex and age.

Analysis of the results of the evaluation of carcinogenic risk population with regard to gender and age showed that the maximum cancer risk is for children population of Aktau (0-6 years) whose risk of occurrence of malignancies is by 1.5-2.5 times higher compared with the same categories of adults. Low population carcinogenic risk for adolescences may be explained by their relatively small number in the population.

To assess the representativeness of the obtained results, we carried out a correlation analysis between the dynamics of changes in atmospheric air of the studied pollutants and changes in the levels of morbidity in all age groups. The list of diseases was compiled on the basis of the "Guide to the International Statistical Classification of Diseases, Injuries and Causes of Death of tenth revision." "Coefficient of Spearman rank correlation" was used to assess the level of morbidity due to air pollution. Calculations were performed using SAS-9 statistical processing of the modular system. The data for the period from 2011 to 2015 were used for calculating.

Analysis of the data shows that there are correlations of moderate strength level of primary morbidity of children living in Aktau with air pollution. In particular, it should be noted that there is a correlation of $0.43-0.60$ between the identified diseases of the urinary system and the content of hydrogen sulfide in the atmosphere of the residential area, carbon monoxide, nitrogen oxides, ammonia, and VOC. Neoplasms link frequency and the presence of hydrogen sulfide in air, carbon monoxide, nitrogen oxides and VOC ( $r$ between 0.43 and 0.6 ); respiratory diseases and the level of hydrogen sulfide, carbon monoxide and oxides of nitrogen $(r=0.50)$ is also noted. In addition, the frequency of congenital anomalies correlates with the content in the atmosphere of nitrogen oxides, ammonia, hydrocarbons, and volatile organic compounds ( $r$ between 0.43 and 0.64 ).

Among the chemicals for which connection of incidence level is often identified, carbon monoxide $r$ from 0.49 to 0.60 (infectious and parasitic diseases, neoplasms, diseases of the endocrine, nutritional, metabolic and immunity systems, disease of the nervous system, eye and its appendages, respiratory diseases, diseases of the genitourinary system) rank first. In second place $-r$ hydrogen sulfide from 0.43 to 0.66 (neoplasms, diseases of the eye and its appendages, diseases of the ear and mastoid process, cardiovascular diseases, respiratory diseases, diseases of the genitourinary system), on the third place $-r$ nitrogen oxides from 0.47 to 0.64 (tumors, cardiovascular diseases, respiratory diseases, congenital anomalies, injuries and poisoning). 
The low level of correlation (within statistical error) dependence is marked for diseases of the digestive system, diseases of the skin and subcutaneous tissue and diseases of the musculoskeletal system.

Analysis of the prevalence of morbidity among children shows that there are correlations of moderate strength with a number of air pollutants. In particular, a connection between the eye and its appendages diseases with the content in the ambient air of sulfur dioxide, hydrogen sulfide, carbon monoxide and oxides of nitrogen ( $r$ from 0.43 to 0.6$)$ is revealed. The following rank place is taken by the diseases of the genitourinary system, $r$ from 0.43 to 0.60 (sulfur dioxide, carbon monoxide, nitrogen oxides). In third place there are diseases of the blood and blood-forming organs, $r$ from 0.41 to 0.6 (hydrogen sulfide, nitrogen oxides).

Among the chemicals, most frequently identified due to the incidence level, first place is occupied by $r$ nitrogen oxides from 0.43 to 0.60 (diseases of the blood and blood-forming organs, cardiovascular diseases, diseases of the eye and its appendages, diseases of the urinary system). The second place is occupied by sulfur dioxide $r$ from 0.49 to 0.60 (endocrine, nutritional, metabolic, and immune system, diseases of the eye and its appendages, ear and mastoid disease, diseases of the genitourinary system, diseases of the musculoskeletal system. In third place there are $r$ hydrogen sulfide from 0.41 to 0.66 (infectious and parasitic diseases, diseases of the blood and blood-forming organs, eye diseases and its appendages).

There is a low level of correlation (within statistical error) for diseases of the nervous system, diseases of the digestive system.

Analysis of the data shows that there are correlations of medium and high power levels of primary morbidity of adolescents living in Aktau with a number of chemical substances, as defined in the atmosphere of residential areas. In particular, the maximum values of correlative links marked for diseases of the endocrine, nutritional, metabolic and immunity (hydrogen sulphide, carbon monoxide, nitrogen oxides, ammonia) $r$ from 0.54 to 0.82 , and diseases of the genitourinary system (hydrogen sulfide, ammonia, hydrocarbons, VOC) $r$ from 0.71 to 0.89 is noted. Then come: $r$ circulatory disease from 0.49 to 0.73 , eye diseases and its appendages $r$ from 0.47 to 0.77 , diseases of the ear and mastoid $r$ from 0.49 to 0.77 (ammonia, hydrocarbons, VOC).

Among the chemicals for which connection of incidence level is often identified, the first place is ammonia (diseases of blood and blood-forming organs, endocrine, nutritional, metabolic and immunity disorders of eye and its appendages, ear disease and the mastoid process, cardiovascular diseases, diseases of the genitourinary system) $r$ from 0.48 to 0.88.In second place - hydrocarbons (diseases of the eye and its appendages, diseases of the ear and mastoid process, diseases of the circulatory system, diseases of the digestive system, diseases of the genitourinary system) $r$ from 0.47 to 0.77 followed by: VOC (cardiovascular diseases, diseases of the eye and its appendages, ear and mastoid diseases, respiratory diseases, diseases of the genitourinary system) $r$ from 0.51 to 0.89 ; hydrogen sulfide (diseases of the blood and blood-forming organs, endocrine, nutritional, metabolic and immunity, respiratory diseases, diseases of the genitourinary system) $r$ from 0.51 to 0.82 .

For infectious and parasitic diseases, diseases of the nervous system, diseases of the skin and subcutaneous tissue, diseases of the musculoskeletal system there is a low level of correlation (within statistical error).

Analysis of the prevalence of morbidity among adolescents indicates that there are correlations of medium and high strength with a number of air pollutants.

In particular, the diseases of the genitourinary system are associated with the content of hydrogen sulphide, ammonia, hydrocarbons and VOC (volatile organic compounds) ( $r$ $0.71-0.88$ ) in the atmosphere followed by: neoplasms (sulphur dioxide, carbon monoxide, 
and hydrocarbons) $r$ of 0.50 to 0.66 ; diseases of the blood and blood-forming organs (hydrogen sulphide, carbon monoxide, ammonia) $r$ from 0.49 to 0.60 ; diseases of the eye and its appendages (ammonia, hydrocarbons, VOC) $r$ from 0.46 to 0.73 .

Among the chemicals, most frequently identified due to the incidence level, leading place are taken by: hydrocarbons (neoplasms, diseases of the ear and mastoid process, diseases of the eye and its appendages, diseases of the genitourinary system) $r$ from 0.46 to 0.77; ammonia (diseases of the blood and blood-forming organs, diseases of the genitourinary system, diseases of the eye and its appendages, diseases of the ear and mastoid process) $r$ from 0.47 to 0.70 ; VOC (diseases of the eye and its appendages, diseases of the genitourinary system, injury and poisoning) $r$ from 0.73 to 0.87 .

For diseases of the nervous system, respiratory diseases, diseases of the digestive system, diseases of the skin and subcutaneous tissue, diseases of the musculoskeletal system there is a low level of correlation (within statistical error).

Analysis of the data shows that there are correlations of medium and high power levels of primary morbidity of the adult population of Aktau, with a number of chemical substances, as defined in the atmosphere of residential areas. In particular, there is a high level of correlations complications of pregnancy and childbirth with the content of hydrogen sulphide in the air, nitrogen oxides, ammonia, hydrocarbons and VOC ( $r$ from 0.49 to 0.81 ). The next rank place is referred to the diseases of the blood and blood-forming organs level which is associated with the presence in the air of hydrogen sulphide, ammonia, hydrocarbons, VOC ( $r$ from 0.71 to 0.78 ), followed by infectious and parasitic diseases (hydrogen sulphide, ammonia, hydrocarbons, VOC) $r$ from 0.77 to 0.84 ), and diseases of the circulatory system (ammonia, hydrocarbons, VOCs) $r$ from 0.43 to 0.73 .

Among the chemicals, most frequently identified due to the leading position of morbidity level, are: hydrogen sulphide (infectious and parasitic diseases, diseases of blood and blood-forming organs, nervous system diseases, disorders of ear and mastoid process, respiratory diseases, digestive diseases, pregnancy complications and childbirth) $r$ from 0.43 to 0.77 ; ammonia (infectious and parasitic diseases, diseases of the blood and bloodforming organs, nervous system diseases, diseases of the ear and mastoid process, diseases of the circulatory system, digestive diseases, complications of pregnancy and childbirth) $r$ from 0.43 to 0.89 ; hydrocarbons (infectious and parasitic diseases, diseases of blood and blood-forming organs, nervous system diseases, circulatory system diseases, complications of pregnancy and childbirth) $r$ from 0.61 to 0.84 ; VOC (infectious and parasitic diseases, diseases of blood and blood-forming organs, nervous system diseases, circulatory system diseases, complications of pregnancy and childbirth) $r$ from 0.61 to 0.84 .

Analysis of the data shows that there are correlations of medium and high power levels of prevalence of morbidity of the adult population of Aktau, with a number of chemical substances, as defined in the atmosphere of residential areas. In particular, there is a high level of correlation between the incidence of diseases of the blood and blood-forming organs and the air containing hydrogen sulphide, ammonia, hydrocarbons and VOC ( $r$ from 0.43 to 0.94$)$. This is followed by neoplasms, diseases of the endocrine, nutritional, metabolic and immune diseases of the circulatory system (hydrogen sulphide, ammonia, hydrocarbons and VOC) $r$ from 0.43 to 0.88 .

Among the chemicals, most frequently identified due to the level of morbidity, the leading place is taken by: VOC (neoplasms, diseases of the blood and blood-forming organs, endocrine, nutritional, metabolic, and immune system, nervous system diseases, diseases of the eye and its appendages, disease the circulatory system, diseases of the musculoskeletal system, complications of pregnancy and childbirth) $r$ from 0.43 to 0.94 ; ammonia (neoplasms, diseases of the blood and blood-forming organs, endocrine, nutritional, metabolic, and immune system, nervous system diseases, diseases of the eye and its appendages, cardiovascular disease, complications of pregnancy and childbirth) $r$ 
from 0.43 to 0.71 ; hydrocarbons (neoplasms, diseases of the blood and blood-forming organs, endocrine, nutritional, metabolic, and immune system, nervous system diseases, circulatory system diseases, complications of pregnancy and childbirth) $r$ from 0.43 to 0.70 .

There is a low level of correlation (within the margin of error) only for the skin and subcutaneous tissue diseases.

Thus according to the results of the study a number of peculiarities in the age groups among people with newly diagnosed diseases are found. In particular in children a high level of connection of neoplasms, diseases of genitourinary system and congenital malformations with air pollutants is revealed. In the group of adolescents maximum connection is established between environmental factors and diseases of the genitourinary system, endocrine, nutritional and metabolic diseases, and immune disorders. In adults the maximum connection is established between atmospheric pollutants and complications of pregnancy and childbirth, blood disorders, diseases of the ear and mastoid process.

In the age groups, the prevalence of disease is characterized by the following features: in children the maximum connection is set for diseases of the eye and its appendages, diseases of the genitourinary system; in adolescents - diseases of the genitourinary system, neoplasms, diseases of blood and blood-forming organs; in adults - diseases of the circulatory system, digestive system diseases and complications of pregnancy and childbirth.

Chemicals that are mostly connected with the level of primary morbidity in the age groups are as follows: in children - hydrogen sulfide, carbon monoxide and nitrogen oxides; in adolescents and adults - ammonia, hydrocarbons, VOCs.

Chemicals that are connected with the level of disease prevalence in the age groups: in children - nitrogen oxides, sulfur dioxide, and hydrogen sulfide; in adolescents and adults ammonia, hydrocarbons, VOCs.

\section{Conclusions}

Thus according to the results of evaluation of individual and population carcinogenic risk to health of people in the city of Aktau and correlation analysis of the population the individual risk of cancer among all age and sex groups can be assessed as very high. As in case of individual as well as population cancer risk, the most vulnerable is children population (0-6 years) of the city. However, it should be noted that the amount of the annual risk of population, as a rule, should not be used for any direct analogies between the levels of actual cancer incidence or mortality rates and the values of these risks.

The results obtained were presented to Aktau city administration to make managerial decisions on development of measures to reduce the risk to public health.

\section{References}

1. Brauer M, Freedman G, Frostad J, van Donkelaar A, et al. Environ Sci Technol. 2016 Jan 5; 50(1), 79-88. doi: 10.1021/acs.est.5b03709. Epub 2015 Dec 4

2. Li Y, Henze DK, Jack D, Henderson BH, Kinney PL. Sci Total Environ. 2016 Jan 1; 539, 515-25. doi: 10.1016/j.scitotenv.2015.08.129. Epub 2015 Sep 15

3. Raaschou-Nielsen O, Beelen R, Wang M, Hoek G, Andersen ZJ, et al. Environ Int. 2016 Feb; 87, 66-73. doi: 10.1016/j.envint.2015.11.007. Epub 2015 Nov 28

4. Zasorin BV, Yermukhanova LS. Gigiyena i sanitariya. Vliyaniye faktorov okruzhayushchey sredy na immunologicheskuyu rezistentnost' organizma. 3, 8-9 (2012) 
5. Zasorin BV, Kurmangaliyev OM, Yermukhanova LS. Osobennosti immunnogo statusa $\mathrm{u}$ naseleniya urbanizirovannykh territoriy s povyshennym soderzhaniyem tyazhelykh metallov. J. Gigiyena i sanitariya. 3, 17-19 (2012)

6. Zhang H, Zhou ZQ, Zhao HY, Xiong ZQ. Huan Jing Ke Xue. 15; 37(1), 28-34. Chinese. (2016)

7. Wang C, Qian X, Li HM, Sun YX, Wang JH. Huan Jing Ke Xue. 15; 37(5), 1662-9. Chinese. (2016)

8. Zasorin BV, Sabyr KK, Iskakov AZH, Kokzhiyek J. Riski zdorov'yu naseleniyu ot vozdeystviya faktorov sredy obitaniya urbanizirovannykh territoriy. Aktobe, (2009)

9. Zasorin BV. J. Meditsinskiy Zapadnogo Kazakhstana. 2(26), 89-94 (2010)

10. Iskakov AZH, Boyev VM, Zasorin BV. J. Gigiyena i sanitariya. 3, 52-54 (2009) 